\title{
Evaluation of milk cathelicidin for detection of bovine mastitis
}

\author{
M. F. Addis, ${ }^{* 1}$ V. Tedde, ${ }^{*}$ G. M. G. Puggioni, ${ }^{*}$ S. Pisanu, ${ }^{*}$ A. Casula, $†$ C. Locatelli,† N. Rota, $†$ V. Bronzo, $\dagger$ \\ P. Moroni, $+\S^{2}$ and S. Uzzau*\# ${ }^{2}$ \\ *Porto Conte Ricerche, SP 55 Porto Conte/Capo Caccia, Km 8.400, Loc. Tramariglio, 07041 Alghero, Italy \\ †Dipartimento di Medicina Veterinaria, Università degli Studi di Milano, Via Celoria 10, 20133 Milan, Italy \\ ‡Dipartimento di Scienze Veterinarie per la Salute, la Produzione Animale e la Sicurezza Alimentare, Università degli Studi di Milano, \\ Via Celoria 10, 20133 Milan, Italy \\ §Animal Health Diagnostic Center, Quality Milk Production Services, Cornell University, 240 Farrier Road, Ithaca, NY 14853 \\ \#Dipartimento di Scienze Biomediche, Università degli Studi di Sassari, Viale S. Pietro 43/B, 07100 Sassari, Italy
}

\begin{abstract}
Mastitis due to intramammary infection is one of the most economically relevant diseases in dairy cows, causing reductions in milk quality and quantity. Currently, mastitis monitoring is based on somatic cell count (SCC) and bacteriologic culture (BC) of milk. Nevertheless, inflammation-specific protein markers might provide more sensitive and reliable assays, enabling immunoassay-based screening strategies. Cathelicidin is an inflammatory protein released in milk that has recently demonstrated fair reliability and diagnostic potential for ewe mastitis. To assess its performance in cows, 531 quarter milk samples from 2 herds were tested using cathelicidin ELISA, SCC, and BC. We found that $29.0 \%$ of samples were positive for cathelicidin, $18.8 \%$ had SCC >200,000 cells/mL, and $13.7 \%$ were BC-positive. Cathelicidin showed a strong positive correlation with SCC as demonstrated by receiver operating characteristics curve analysis and by the clustering of cathelicidin-negative and cathelicidin-positive samples in association with low and high SCC values, respectively. For evaluating the diagnostic performance of a novel test, $\mathrm{BC}$ cannot be considered a reliable gold standard for true disease status because of its known limitations. Therefore, we assessed the sensitivity (Se) and specificity (Sp) of the milk cathelicidin ELISA using a latent class analysis approach together with BC and SCC by considering different diagnostic thresholds to identify the preferred Se/Sp combination. We modeled conditional dependence of cathelicidin and SCC to account for their close association. The cathelicidin ELISA showed higher Se than SCC and BC for almost
\end{abstract}

Received May 5, 2016.

Accepted June 28, 2016.

${ }^{1}$ Corresponding author: addis@portocontericerche.it

${ }^{2}$ These authors contributed equally to this work. all threshold combinations. In fact, at the best-performing threshold combination, the Se of cathelicidin was $80.6 \%, 6.2$ percentage points higher than that of SCC $>200,000$ cells $/ \mathrm{mL}(74.4 \%)$ and similar to that of SCC $>100,000$ cells $/ \mathrm{mL}(80.2 \%)$. Most importantly, this Se was obtained with a loss in Sp of only 1.4 percentage points compared with SCC >200,000 cells/mL $(94.9 \%$ Sp for cathelicidin vs. $96.3 \%$ for SCC >200,000). The limited Se of $\mathrm{BC}(38.8 \%)$ was also confirmed in this study, and BC showed a slightly lower Sp than both cathelicidin and SCC for most of threshold combinations. This study confirmed that cathelicidin is released in the milk of cows with mastitis and that its presence is highly correlated with SCC. The measurement of cathelicidin by ELISA may hold significant potential for improving the sensitivity of mastitis detection in dairy cows while maintaining high specificity.

Key words: mastitis, cathelicidin, dairy cow, ELISA

\section{INTRODUCTION}

Mastitis is a major cause of economic loss in the dairy industry worldwide. It remains one of the most relevant diseases in dairy cows, responsible for changes in milk quality and reduced milk production (Bradley, 2002; Le Roux et al., 2003; De Vliegher et al., 2012). However, despite its relevance, mastitis can be difficult to detect before the onset of clinical symptoms, before the appearance of milk quality alterations, or when the case is subclinical. The consequences of delayed detection are delayed interventions to treat or control infection. Therefore, efforts are needed to identify tools that can enable the effective and timely detection of mastitis. The most widely accepted indicator for monitoring mastitis is SCC (Schukken et al., 2003), but physiological factors, seasonal variations, and other stressors can produce changes in SCC that are unrelated to an IMI (Schepers et al., 1997; Schukken et al., 2003). Increased SCC indicates only that an IMI may have occurred (Dohoo and Leslie, 1991; Dohoo, 2001; Fox, 2013), and 
the presence of a low number of cells in milk is only very likely associated with the absence of mastitis. The threshold of 200,000 cells $/ \mathrm{mL}$ is currently believed to provide the least diagnostic error when determining whether an IMI is present (Dohoo and Leslie, 1991; Schukken et al., 2003; Bradley and Green, 2005).

Considering the above limitations, implementation of other more specific markers of inflammation might prove useful, either in association with SCC or as an alternative, particularly if they open the way to developing field measurement systems (such as lateral flow devices or dipsticks), in-line systems, or other dedicated immunoassay formats (Viguier et al., 2009; Gurjar et al., 2012). Several immune-related molecules released in milk in response to a bacterial infection have been suggested for use as udder health markers (Ceciliani et al., 2012; Wheeler et al., 2012; Miglio et al., 2013), and indications of the release of cathelicidin in the milk of cows with mastitis have been provided by several authors (Murakami et al., 2005; Smolenski et al., 2007; Zhang et al., 2015). Cathelicidins are innate immune effectors with direct antimicrobial activity and potent proinflammatory and chemotactic functions (Zanetti, 2004, 2005; Wiesner and Vilcinskas, 2010). Seven cathelicidin genes have been described in cattle, of which 6 are expressed in milk leukocytes (Whelehan et al., 2014). In neutrophil secondary granules, cathelicidin represents about $4 \%$ of the protein content (Zanetti et al., 1991), and it is released upon exposure to a pathogen-associated molecular pattern, often before the onset of clinical symptoms (Lippolis and Reinhardt, 2005; Smolenski et al., 2007; Addis et al., 2011). Cathelicidin is also produced and released by epithelial cells (including milk-secreting cells) early and efficiently upon exposure to pathogen-associated molecular patterns (Chromek et al., 2006; Addis et al., 2011, 2013), and it is abundant in neutrophil extracellular traps formed in milk upon infection (Lippolis et al., 2006; Reinhardt et al., 2013; Pisanu et al., 2015). A further advantage of cathelicidin as an inflammation marker is that it is undetectable in milk from healthy udders, but it increases quickly and significantly upon exposure to a microbial stimulus and returns rapidly to baseline if an infection is not established (Saad and Ostensson, 1990; Sladek et al., 2005).

Smolenski et al. (2011) showed promising results concerning cathelicidin abundance in mastitic cow milk by means of western immunoblotting. Recently, we have identified cathelicidin among the most relevant proteins released in ewe's milk in mastitis and have demonstrated its diagnostic value with a dedicated pan-cathelicidin ELISA developed in our laboratories (Addis et al., 2011, 2013, 2016).
Based on these premises, the aim of this work was to investigate the diagnostic potential of cathelicidin as a mastitis indicator in cow milk, and to assess the performance of our cathelicidin ELISA for its detection compared with SCC and bacteriologic culture (BC) results.

\section{MATERIALS AND METHODS}

\section{Farm Characteristics and Milk Sampling}

The study was carried out on 531 quarter milk samples. Before sample collection, teat ends were carefully cleaned and disinfected with disposable towels embedded with chlorhexidine. First streams of foremilk were discharged, and then approximately $10 \mathrm{~mL}$ of milk was collected aseptically from each teat into sterile vials. Samples were brought to the laboratory and stored at $4^{\circ} \mathrm{C}$ for a maximum of $24 \mathrm{~h}$ until bacteriological assays and SCC tests were performed. Samples were collected from 2 herds: herd A had an average of 1,200 lactating cows and herd B had an average of 150 lactating cows. Both farms were part of a voluntary herd health monitoring program carried out over several years by the University of Milan, in which cows were sampled by quarter for culture after calving, and based on monthly DHIA test-day linear score, all cows with scores $>4.0$ (SCC $\geq 200,000$ cells $/ \mathrm{mL}$ ) were screened with the California Mastitis Test to identify quarters with high SCC. The samples included in the study were received at the university laboratory in February 2015.

\section{Bacteriological Analysis and Isolates}

Bacteriological analysis was performed according to the standards of the National Mastitis Council (1999). Ten microliters of each milk sample was spread onto blood agar plates ( $5 \%$ defibrinated sheep blood). Plates were incubated aerobically at $37^{\circ} \mathrm{C}$ and examined after $24 \mathrm{~h}$. Colonies were provisionally identified based on Gram stain, morphology, and hemolysis patterns, and the numbers of each colony type were recorded. Representative colonies were then subcultured on blood agar plates and incubated again at $37^{\circ} \mathrm{C}$ for $24 \mathrm{~h}$ to obtain pure cultures. Catalase and coagulase production were tested for gram-positive cocci. Gram-negative isolates were identified using colony morphology, Gram-staining characteristics, oxidase, and biochemical reactions on MacConkey's agar. Samples with growth of 3 or more pathogens were considered contaminated. Somatic cell count was determined using an automated counter (Bentley Somacount 150; Bentley Instruments, Chaska, $\mathrm{MN})$. 


\section{Pan-Cathelicidin ELISA}

Evaluation of cathelicidin in milk was carried out using a pan-cathelicidin sandwich ELISA developed in-house as described previously (Addis et al., 2016), with minor modifications. The pan-cathelicidin peptide (PCP) sequence used for generating monoclonal antibodies included a region with identity of $99 \%$ with CTHL1_BOVIN, 72\% with CTHL2_BOVIN, $69 \%$ with CTHL3_BOVIN, $68 \%$ with CTHL4_BOVIN, $80 \%$ with CTHL5_BOVIN, 73\% with CTHL6_BOVIN, and 73\% with CTHL7_BOVIN, respectively, according to the nonredundant UniProtKB/SwissProt Database (www. uniprot.org). The PCP was synthesized using the solidphase procedure of Merrifield (1963) with a microwave single-mode Discover SPS reactor insert in a peptide synthesizer Liberty (CEM Corporation, Matthews, NC) and fluorenylmethyloxycarbonylchloride (Fmoc)based solid-phase peptide synthesis; Fmoc amino acids were from Novabiochem (Laufelfingen, Switzerland). Reverse-phase high-pressure liquid chromatography, carried out on an HP 1200 instrument (Agilent Technologies, Santa Clara, CA) connected to an UV-Vis detector, was used to purify the crude peptide (Mura et al., 2011). The purified peptide mixture was then evaluated by mass spectrometry on a quadrupole timeof-flight (Q-TOF) hybrid instrument with a nano Zspray source (Waters, Manchester, UK; Maddau et al., 2009) after injection of the peptide solution into the ion source.

Anti-PCP monoclonal antibodies were produced by Abbiotec (San Diego, CA) with PCP as the antigen. The 2 best-performing monoclonal antibodies were selected and validated by Western immunoblot against PCP and against milk samples from sheep with mastitis as described previously (Addis et al., 2016). The PCP ELISA was developed in a sandwich format following standard protocols (Danowski et al., 2013; Miglio et al., 2013; Trend et al., 2015). Capture antibodies were absorbed overnight at $4^{\circ} \mathrm{C}$ on MaxiSorp Nunc-Immuno 96 well plates (Sigma-Aldrich, St. Louis, MO). Wells were rinsed with Tris-buffered saline solution, and then blocked with $5 \%$ bovine serum albumin in Tris-buffered saline solution supplemented with $0.05 \%$ Tween 20 . After washing with Tris-buffered saline with Tween, milk samples were incubated in the wells for $1 \mathrm{~h}$ at room temperature, and the wells were washed again. Detection antibodies conjugated with horseradish peroxidase were added to the plate, incubated for $1 \mathrm{~h}$ at room temperature, and washed again; reactivity was visualized using a 3,3',5,5'-tetramethylbenzidine substrate (Sigma-Aldrich). The reaction was stopped with $2 M$ $\mathrm{H}_{2} \mathrm{SO}_{4}$, and optical density (OD) values were acquired on a plate reader at $450 \mathrm{~nm}\left(\mathrm{OD}_{450}\right)$. For absorbance normalization, 6 culture-negative samples with $<50,000$ cells $/ \mathrm{mL}$ were included in all ELISA plates. Then, we subtracted the average $\mathrm{OD}_{450}+3 \mathrm{SD}$ of the 6 internal normalization samples from all $\mathrm{OD}_{450}$ values to obtain the normalized $\mathrm{OD}_{450}$ values $\left(\mathrm{NOD}_{450}\right)$.

\section{Statistics}

According to the Shapiro-Wilk normality test, the data showed a non-normal distribution. Therefore, we applied a nonparametric Mann-Whitney U-test. Descriptive statistical analysis (medians and interquartile ranges) was carried out using GraphPad Prism version 5.03 for Windows (GraphPad Software, La Jolla, CA). MedCalc Statistical Software version 15.2.2 (MedCalc Software bvba, Ostend, Belgium) was used to generate receiver operating characteristic curves.

Latent class analysis (LCA) was carried out using BayesianLatentClassModels (BLCM) version 1.13 (www.nandinidendukuri.com/blcm) to obtain sensitivity (Se), specificity (Sp), and $95 \%$ credible intervals (CrI) (Dendukuri and Joseph, 2001; Dendukuri et al., 2009). The latent class model requires that 3 assumptions be satisfied to validate the method: a different prevalence in the populations, constant Se and Sp of the tests in the populations, and conditional independence of the tests. Tests that are not conditionally independent need to be modeled. The difference in prevalence was satisfied because BC positivity was $19 \%$ in herd $\mathrm{A}$ and $10 \%$ in herd $\mathrm{B}$. Constant Se and $\mathrm{Sp}$ in both herds was verified by running a separate LCA for each herd. Based on the model diagnostics, the assumption of conditional independence was not satisfied for cathelicidin and SCC. Therefore, we modeled the conditional dependence between these 2 parameters. We used uninformative priors for cathelicidin ELISA and SCC using the default settings in the BLCM software, and reliable estimates for Se and Sp of BC on a single milk sample were available in the scientific literature (Dohoo et al., 2011). We used the Se and Sp and relative confidence interval reported by these authors as priors. Gibbs sampling was run by discarding the first 500 iterations at the burn-in phase and making inferences on the subsequent 10,000. Convergence of the Gibbs sampler algorithm was verified by examining the trace plots for all runs.

Test performances were evaluated at different thresholds. For ELISA, adding to the optimal cutoff value resulting from normalization with negative samples $\left(\mathrm{NOD}_{450}=0.000\right)$, we also assessed a higher threshold of $\mathrm{NOD}_{450}=0.014$ based on previous findings (Addis et al., 2016). For SCC, we considered 3 different thresholds: the conventional 200,000 cells $/ \mathrm{mL}$, estimated to provide the most desirable Se versus $\mathrm{Sp}$, and 2 lower 


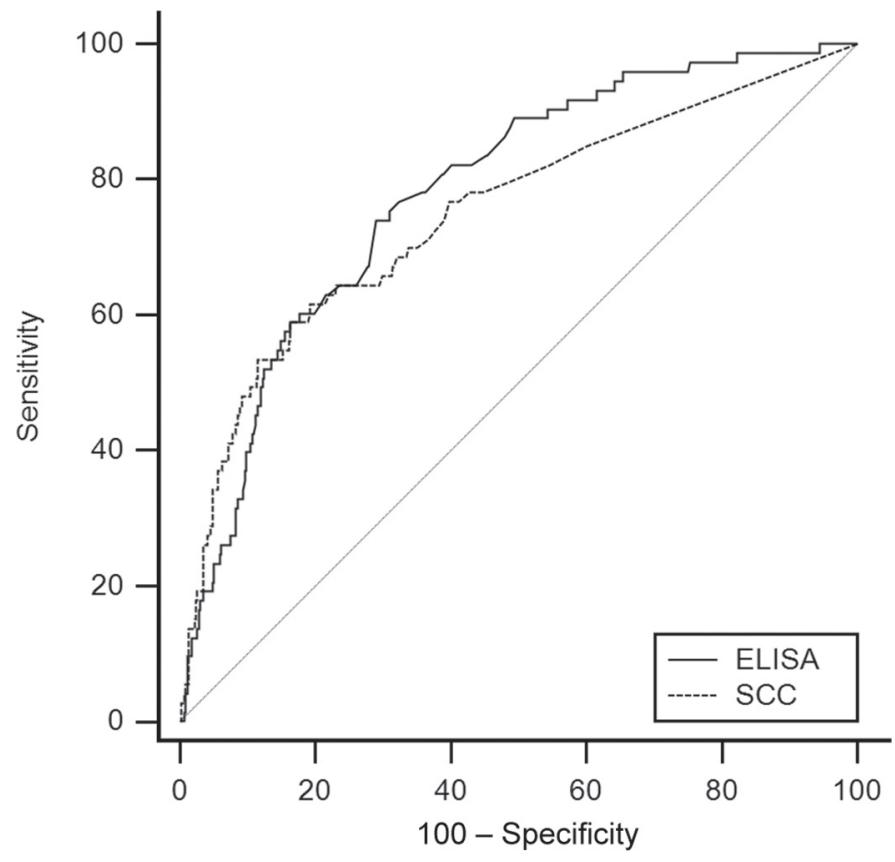

Figure 1. Receiver operating characteristic (ROC) curves illustrating the relationship of cathelicidin ELISA and SCC (cells $/ \mathrm{mL}$ ) with bacteriologic culture (BC) as the reference. The ROC curves reported in the figure describe the tradeoff between sensitivity and specificity of the cathelicidin ELISA (solid line) and SCC (dotted line) compared with $\mathrm{BC}$ results as the reference, respectively. The $45^{\circ}$ diagonal of the ROC space corresponds to the random chance line.

thresholds of 150,000 and 100,000 cells/mL (Dohoo and Leslie, 1991; Schukken et al., 2003; Bradley and Green, 2005).

\section{RESULTS}

\section{Relationship of Cathelicidin and SCC with Bacteriologic Culture}

All 531 quarter milk samples were subjected to cathelicidin ELISA, SCC (cells $/ \mathrm{mL}$ ), and BC. As a result, $29.0 \%$ of the samples were positive for cathelicidin, $18.8 \%$ had SCC >200,000 cells $/ \mathrm{mL}$, and $13.7 \%$ were positive for BC. To estimate the relationship of cathelicidin ELISA and SCC with BC, we generated receiver operating characteristic curves by setting $\mathrm{BC}$ results as the reference (Figure 1). Area under the curve values for cathelicidin ELISA and SCC were 0.78 (95\% CI: 0.74-0.81) for cathelicidin and 0.75 (95\% CI: 0.71-0.79) for SCC, respectively. Sensitivity, Sp, and diagnostic thresholds were assessed by LCA as described in the next section.

We evaluated the distribution of all cathelicidinnegative and cathelicidin-positive samples accord- ing to SCC. As shown by the box plots in Figure 2, cathelicidin-negative and cathelicidin-positive samples displayed a statistically significant separation (MannWhitney test, $P<0.0001$ ) around low and high SCC, respectively. Median and interquartile range SCC values are reported in Table 1.

\section{Diagnostic Performance of Cathelicidin, SCC and BC, and Definition of Diagnostic Thresholds}

The Se and Sp of cathelicidin ELISA, SCC, and BC were evaluated by LCA in a Bayesian framework at different threshold combinations, and results are reported in Table 2. The cathelicidin ELISA showed superior Se compared with both SCC and BC in 5 out of 6 of the diagnostic combinations evaluated, although with some overlapping of the respective credible interval values. The most interesting result, however, was that the Se of cathelicidin was higher by 6.2 percentage points when applying the $\mathrm{NOD}_{450}=0.014$ threshold than the Se of SCC >200,000 cells $/ \mathrm{mL}$ (80.6\% vs. $74.4 \%$, respectively). This finding was at the expense of a minimal loss in Sp of 1.4 percentage points $(94.9 \%$ vs. $96.3 \%$, respectively). The Se of cathelicidin at the $\mathrm{NOD}_{450} 0.014$ threshold was comparable to that of SCC $>100,000$ cells $/ \mathrm{mL}(80.6 \%$ vs. $80.2 \%$, respectively), but with a Sp close to that of SCC $>200,000$ cells $/ \mathrm{mL}$. The

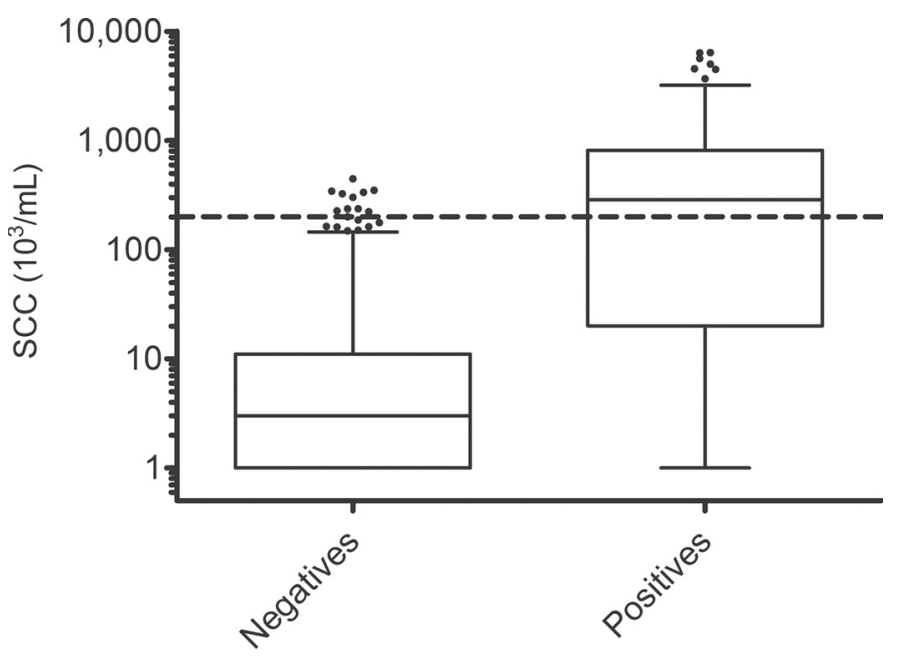

Figure 2. Distribution of cathelicidin-negative and cathelicidinpositive samples according to the SCC on a logarithmic scale. The box indicates values falling within the 25 th and 75 th percentiles, with the central line indicating the median value. Whiskers indicate values falling within the 2.5th and 97.5th percentiles, and the individual dots represent values falling outside the whiskers. The dashed line indicates an SCC threshold of 200,000 cells $/ \mathrm{mL}$. The difference between the negative and the positive group was statistically significant $(P<$ $0.0001 ; \mathrm{n}=531)$. 
Table 1. Median and interquartile ranges of SCC (cells $/ \mathrm{mL})$ in cathelicidin-negative and cathelicidin-positive milk samples

\begin{tabular}{lccc}
\hline \multirow{2}{*}{ Sample } & 25 th percentile & Median & 75th percentile \\
& SCC & SCC & SCC \\
\hline Cathelidicin-negative $(\mathrm{n}=377)$ & 1,000 & 3,000 & 11,000 \\
Cathelidicin-positive $(\mathrm{n}=154)$ & 20,000 & 286,000 & 815,000 \\
\hline
\end{tabular}

limited Se of BC was confirmed in this study (38.8\%), and $\mathrm{BC}$ also showed lower $\mathrm{Sp}$ than the other tests when considering the $\mathrm{NOD}_{450} 0.014$ threshold.

\section{Relationship of Cathelicidin and SCC Results with the Isolated Microorganisms}

Table 3 reports the distribution of results according to isolated microorganism based on the conventional SCC threshold of 200,000 cells/mL and the cathelicidin ELISA threshold of $\mathrm{NOD}_{450}=0.014$ selected according to the above findings. In Table 3, Staphylococcus aureus, Streptococcus dysgalactiae, Streptococcus uberis, and Prototheca spp. are reported independently, and all CNS, other gram-positives, and gram-negatives are grouped into separate classes. Of all BC-negative samples, $95.2 \%$ of those $<200,000$ cells $/ \mathrm{mL}$ were negative for cathelicidin and $85.5 \%$ of those $>200,000$ cells/ $\mathrm{mL}$ were positive. However, 6 BC-positive samples $<200,000$ cells/mL were positive for cathelicidin. Half of these were positive for Strep. uberis. On the other hand, 4 BC-positive samples $>200,000$ cells $/ \mathrm{mL}$ were negative for cathelicidin and 3 of them were positive for CNS.

\section{DISCUSSION}

Measurement of SCC in milk has long been established as the standard for monitoring mastitis in cows, and the presence of SCC $>200,000$ cells/mL is typically considered a strong indicator of mastitis (Schukken et al., 2003). Nevertheless, protein biomarkers measured with dedicated immunoassays have the potential to improve mastitis detection (Viguier et al., 2009). Building on the results obtained in dairy sheep (Addis et al., 2016), this study demonstrated increased Se and Sp of milk cathelicidin, measured by ELISA, for the detection of bovine mastitis compared with SCC and BC. We also found a strong positive correlation between cathelicidin and SCC, both by the comparable areas under the curve for cathelicidin and SCC in relation to $\mathrm{BC}$ and by the distribution of cathelicidin-negative and -positive samples around low and high SCC values, respectively.

We assessed the Se and Sp of the cathelicidin ELISA by LCA compared with SCC and BC. Building on crossclassification of the observed or "manifest" variables into an unobserved "latent" variable, LCA probabilistically groups each observation into one latent class. In this way, the lack of a gold standard for true disease status is obviated (Hui and Walter, 1980), providing a way to evaluate the Se and Sp of a novel diagnostic test when a reliable reference assay is not available (Georgiadis et al., 2003). This approach is finding increasing application in mastitis research (Koop et al., 2011; Fosgate et al., 2013; Vissio et al., 2014; Addis et al., 2016). In fact, $\mathrm{BC}$ cannot be considered the perfect assay for defining true disease status, because its use as a reference may lead to possible errors in estimating the Se and Sp of a novel diagnostic test (Enøe et al., 2000). Adding to practical factors, the limitations of $\mathrm{BC}$ originate from

Table 2. Means of sensitivity and specificity (95\% credible intervals in parentheses) obtained for cathelicidin, SCC, and bacteriological culturing upon application of the latent class analysis approach by modeling conditional dependence of cathelicidin and $\mathrm{SCC}^{1}$

\begin{tabular}{lccr}
\hline & \multicolumn{2}{c}{ SCC threshold } & \multicolumn{1}{c}{$>200,000$} \\
\cline { 2 - 5 } ELISA threshold & \multicolumn{1}{c}{$>100,000$} & & $>150,000$ \\
\hline NOD $_{450}=0.000$ & $81.3(65.2-94.6) / 86.0(80.3-91.5)$ & $83.9(67.2-96.5) / 86.1(80.3-91.4)$ & $83.8(66.6-96.1) / 85.8(80.0-91.2)$ \\
Cathelicidin & $78.1(59.7-93.6) / 91.8(86.4-96.7)$ & $76.4(59.1-92.4) / 94.2(89.2-98.0)$ & $75.0(55.9-92.1) / 96.1(91.5-99.3)$ \\
SCC & $38.8(35.5-42.2) / 92.8(91.2-94.4)$ & $38.8(35.5-42.2) / 92.7(91.0-94.3)$ & $38.9(35.6-42.3) / 92.7(91.0-94.2)$ \\
BC & $76.0(59.5-92.1) / 94.3(89.0-98.5)$ & $79.5(61.7-93.8) / 94.5(89.3-98.7)$ & $80.6(63.2-93.7) / 94.9(90.1-98.7)$ \\
NOD $450=0.014$ & $80.2(63.5-93.8) / 92.5(86.8-97.8)$ & $77.5(59.6-92.6) / 94.4(89.4-98.1)$ & $74.4(57.4-89.3) / 96.3(91.8-99.3)$ \\
Cathelicidin & $38.8(35.4-42.1) / 92.8(91.1-94.4)$ & $38.8(35.5-42.2) / 92.7(91.0-94.3)$ & $38.8(35.5-42.2) / 92.8(91.1-94.3)$ \\
SCC & BC &
\end{tabular}

${ }^{1}$ Results are based on 2 optimized normalized optical density at $450 \mathrm{~nm}\left(\mathrm{NOD}_{450}\right)$ ELISA thresholds and 3 SCC thresholds. 
Table 3. Combined results for SCC, cathelicidin, and bacteriological culturing

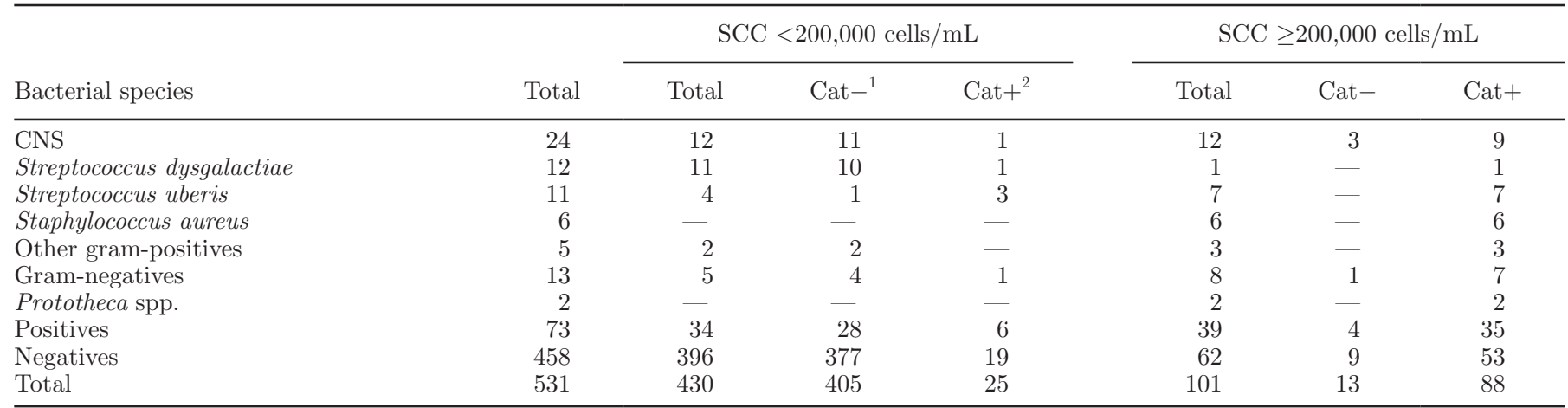

${ }^{1}$ Cathelicidin ELISA with normalized optical density at $450 \mathrm{~nm}\left(\mathrm{NOD}_{450}\right)<0.014$.

${ }^{2}$ Cathelicidin ELISA with $\mathrm{NOD}_{450} \geq 0.014$.

its low Se due to intermittent shedding of bacteria in milk, the possible presence of low bacterial loads, the fastidiousness of certain microorganisms to grow in culture, the effective reduction the number of bacteria in milk by the host immune response, and the presence of antimicrobials in milk, including host-produced antimicrobial molecules (Walker et al., 2011; Ruegg and Pantoja, 2013). If using $\mathrm{BC}$ as a reference, a falsenegative $\mathrm{BC}$ result would erroneously be considered a false positive for the novel assay being evaluated, leading to underestimation of its diagnostic performance. Bacteriologic culture can also produce false-positive results upon isolation of contaminant or nonpathogenic microorganisms, leading to underestimation of the $\mathrm{Sp}$ of the evaluated assay. In addition, $\mathrm{BC}$ does not enable discrimination among more and less virulent strains of the same species, and their ability to cause mastitis. Concerning SCC, a threshold of 200,000 cells/mL provides the best diagnostic performance, but lower SCC thresholds may be more adequate in some cases (Dohoo and Leslie, 1991; Schukken et al., 2003; Ruegg and Pantoja, 2013). It is known that a low number of somatic cells in milk is associated with an absence of mastitis, but nonspecific SCC increases can occur, and high SCC can persist after the infection resolves (Schepers et al., 1997; Schukken et al., 2003; Fox, 2013). Considering these limitations, LCA may be a more reliable approach for estimating the Se and Sp of a novel diagnostic test, given that model assumptions and performances are correctly verified (van Smeden et al., 2014).

With LCA, the milk cathelicidin ELISA showed a higher Se than SCC and BC in almost all combinations evaluated. Of particular relevance was the higher Se (6.2 percentage points) obtained at the expense of a minor loss in Sp (1.4 percentage points) when compared with SCC >200,000 cells/mL. Notably, cathelicidin showed Se comparable to a threshold of SCC $>100,000$ cells $/ \mathrm{mL}$ with $\mathrm{Sp}$ comparable to a threshold of SCC
$>200,000$ cells $/ \mathrm{mL}$. This result is especially relevant when favoring disease control versus disease eradication, as in the case of mastitis, where maintaining a good level of $\mathrm{Sp}$ is preferable to reaching the highest possible Se levels (Banoo et al., 2010).

Adding to its remarkable diagnostic performance, cathelicidin presents numerous advantages as a mastitis biomarker compared with SCC. Together with the fact that it can be measured by ELISA in relatively lower-resource laboratories without requiring dedicated cell counting instrumentation, cathelicidin lends itself to the development of other immunoassay tools to be used for field testing in the form of dipsticks or immunochromatographic devices (e.g., lateral flow assays) for applications similar to those of the California Mastitis Test (Whyte et al., 2005) or electrical conductivity measurements, especially considering the limited Se and Sp of the latter methods (Pyörälä, 2003). Similarly, the implementation of immunoassay-based strategies enabling in-line detection in herd management systems may have potential. Different enzymes have been used for this purpose to date, including lactate dehydrogenase (Chagunda et al., 2006; Hiss et al., 2007) or $N$-acetyl$\beta$-D-glucosaminidase (Mattila et al., 1986; Holdaway et al., 1996; Nielsen et al., 2005). The development of enzyme-based assays is easier because of their intrinsic reactivity but is counterbalanced by lower Se and $\mathrm{Sp}$ (Nyman et al., 2016). Instead of by measuring enzyme activity, mastitis-related biomarkers can be detected by developing dedicated immunoassay strategies, provided that reliable antibodies are available to warrant assay robustness and reproducibility (Baker, 2015). Advancements in laboratory and field immunoassay technologies have improved the reproducibility, sensitivity, and specificity of nonenzymatic molecule measurement and can provide new means of developing inexpensive and practical alternatives (Viguier et al., 2009; Gurjar et al., 2012). 
Several other nonenzymatic, immune-defense proteins have been proposed as mastitis markers (Ceciliani et al., 2012; Wheeler et al., 2012; Miglio et al., 2013), including serum amyloid A and haptoglobin (Eckersall et al., 2001; Hiss et al., 2007; O'Mahony et al., 2006). Serum amyloid A and haptoglobin are mainly produced in the liver but are also found in the inflamed udder (McDonald et al., 2001; Hiss et al., 2004). A sandwich ELISA for serum amyloid A (Tridelta phase range SAA kit; Tridelta Development Ltd., Co. Wicklow, Ireland) has been developed and is commercially available. It will be of interest to assess the respective diagnostic performance of these assays and the cathelicidin ELISA in comparable sample groups.

As a biomarker, cathelicidin is directly linked to mastitis, being involved in innate immune response processes. It is produced by both mammary epithelial cells and immune cells, and its rapid release upon entry of a pathogenic microorganism in the udder may enable earlier detection of infection (Smolenski et al., 2011; Addis et al., 2013). Considering its crucial role in the first steps of inflammation and in the host response to infection, the measurement of cathelicidin may also represent a useful research tool in studies aimed at investigating microbial pathogenicity and the dynamics of the host response to infecting microorganisms. By looking at the detailed results of cathelicidin, SCC, and $\mathrm{BC}$ in relation to the microorganism isolated from milk, 6 of 34 BC-positive samples had SCC $<200,000$ cells/ $\mathrm{mL}$ but were positive for cathelicidin, suggesting the presence of an inflammatory condition that would go undetected if relying only on SCC. These cases may relate to early IMI stages or subclinical mastitis, as suggested by other authors (Smolenski et al., 2011), and would account for the higher Se of cathelicidin compared with SCC. Notably, half of these samples were positive for Strep. uberis. On the other hand, 4 of 39 BC-positive samples with SCC $>200,000$ cells/ $\mathrm{mL}$ were negative for cathelicidin, and 3 of those had CNS. Adding to the possibility of nonspecific increases in SCC or lack of cathelicidin Se, it should be noted that some microorganisms such as CNS can lead to SCC increases without compromising milk quality or production performance, and are associated with measurable increases in milk yield (Schukken et al., 2009; Piepers et al., 2013). That is, CNS or other microbial colonizers of the udder might cause slight SCC increases without inducing cathelicidin release (Fox, 2013). From other studies, we know that when pathogen clearing is successful, spent neutrophils undergo a "clean death" without degranulation or neutrophil extracellular trap release and are efficiently removed by macrophages or dendritic cells ( $\mathrm{Lu}$ et al., 2012). Nevertheless, we cannot rule out that in some chronic infections or in later stages of resolving infections, cathelicidin may no longer be present. Further studies on the dynamics of colonization/infection and on the role of pathogenicity traits in influencing cathelicidin release will help elucidate the relationships among SCC, cathelicidin, and microbial features.

In conclusion, this study confirmed that cathelicidin is released in the milk of cows with mastitis, that its presence is highly correlated with SCC, and that its measurement by ELISA may hold significant potential for improving the sensitivity of mastitis detection in dairy cows while maintaining high specificity.

\section{ACKNOWLEDGMENTS}

This work was funded by Regione Autonoma della Sardegna (Sardinia, Italy) with funds granted to the Sardinia Regional Science and Technology Park (Tramariglio, Alghero, Italy).

\section{REFERENCES}

Addis, M. F., S. Pisanu, S. Ghisaura, D. Pagnozzi, G. Marogna, A Tanca, G. Biosa, C. Cacciotto, A. Alberti, M. Pittau, T. Roggio, and S. Uzzau. 2011. Proteomics and pathway analyses of the milk fat globule in sheep naturally infected by Mycoplasma agalactiae provide indications of the in vivo response of the mammary epithelium to bacterial infection. Infect. Immun. 79:3833-3845. http:// dx.doi.org/10.1128/IAI.00040-11.

Addis, M. F., S. Pisanu, G. Marogna, T. Cubeddu, D. Pagnozzi, C. Cacciotto, F. Campesi, G. Schianchi, S. Rocca, and S. Uzzau. 2013. Production and release of antimicrobial and immune defense proteins by mammary epithelial cells following Streptococcus uberis infection of sheep. Infect. Immun. 81:3182-3197. http://dx.doi. org/10.1128/IAI.00291-13.

Addis, M. F., V. Tedde, S. Dore, S. Pisanu, G. M. G. Puggioni, A. M. Roggio, D. Pagnozzi, S. Lollai, E. A. Cannas, and S. Uzzau. 2016. Evaluation of milk cathelicidin for detection of dairy sheep mastitis. J. Dairy Sci. http://dx.doi.org/10.3168/jds.2015-10293.

Baker, M. 2015. Reproducibility crisis: Blame it on the antibodies. Nature 521:274-276. http://dx.doi.org/10.1038/521274a.

Banoo, S., D. Bell, P. Bossuyt, A. Herring, D. Mabey, F. Poole, P. G. Smith, N. Sriram, C. Wongsrichanalai, R. Linke, R. O'Brien, M. Perkins, J. Cunningham, P. Matsoso, C. M. Nathanson, P. Olliaro, R. W. Peeling, and A. Ramsay. 2010. Evaluation of diagnostic tests for infectious diseases: General principles. Nat. Rev. Microbiol. 8:S17-S29. http://dx.doi.org/10.1038/nrmicro1523.

Bradley, A., and M. Green. 2005. Use and interpretation of somatic cell count data in dairy cows. In Pract. 27:310-315. http://dx.doi. org/10.1136/inpract.27.6.310.

Bradley, A. 2002. Bovine mastitis: An evolving disease. Vet. J. 164:116-128. http://dx.doi.org/10.1053/tvjl.2002.0724.

Ceciliani, F., J. J. Ceron, P. D. Eckersall, and H. Sauerwein. 2012 Acute phase proteins in ruminants. J. Proteomics 75:4207-4231. http://dx.doi.org/10.1016/j.jprot.2012.04.004.

Chagunda, M. G., T. Larsen, M. Bjerring, and K. L. Ingvartsen. 2006 L-Lactate dehydrogenase and N-acetyl-beta-D-glucosaminidase activities in bovine milk as indicators of non-specific mastitis. J. Dairy Res. 73:431-440. http://dx.doi.org/10.1017/S0022029906001956.

Chromek, M., Z. Slamová, P. Bergman, L. Kovács, L. Podracká, I Ehrén, T. Hökfelt, G. H. Gudmundsson, R. L. Gallo, B. Agerberth, and A. Brauner. 2006. The antimicrobial peptide cathelicidin protects the urinary tract against invasive bacterial infection. Nat. Med. 12:636-641. http://dx.doi.org/10.1038/nm1407. 
Danowski, K., J. J. Gross, H. H. D. Meyer, and H. Kliem. 2013. Effects of induced energy deficiency on lactoferrin concentration in milk and the lactoferrin reaction of primary bovine mammary epithelial cells in vitro. J. Anim. Physiol. Anim. Nutr. (Berl.) 97:647-655. http://dx.doi.org/10.1111/j.1439-0396.2012.01305.x.

De Vliegher, S., L. K. Fox, S. Piepers, S. McDougall, and H. W. Barkema. 2012. Invited review: Mastitis in dairy heifers: Nature of the disease, potential impact, prevention, and control. J. Dairy Sci. 95:1025-1040. http://dx.doi.org/10.3168/jds.2010-4074.

Dendukuri, N., A. Hadgu, and L. Wang. 2009. Modeling conditional dependence between diagnostic tests: A multiple latent variable model. Stat. Med. 28:441-461. http://dx.doi.org/10.1002/ sim.3470.

Dendukuri, N., and L. Joseph. 2001. Bayesian approaches to modeling the conditional dependence between multiple diagnostic tests. Biometrics 57:158-167.

Dohoo, I. 2001. Setting SCC cutpoints for cow and herd interpretation. Pages 10-18 in Natl. Mastitis Counc. Ann. Mtg. Proc., Reno, NV. Natl. Mastitis Counc. Inc., Madison, WI.

Dohoo, I. R., and K. E. Leslie. 1991. Evaluation of changes in somatic cell counts as indicators of new intramammary infections. Prev. Vet. Med. 10:225-237. http://dx.doi.org/10.1016/01675877(91)90006-N.

Dohoo, I. R., J. Smith, S. Andersen, D. F. Kelton, and S. Godden. 2011. Diagnosing intramammary infections: Evaluation of definitions based on a single milk sample. J. Dairy Sci. 94:250-261. http://dx.doi.org/10.3168/jds.2010-3559.

Eckersall, P. D., F. J. Young, C. McComb, C. J. Hogarth, S. Safi, A. Weber, T. McDonald, A. M. Nolan, and J. L. Fitzpatrick. 2001. Acute phase proteins in serum and milk from dairy cows with clinical mastitis. Vet. Rec. 148:35-41.

Enøe, C., M. P. Georgiadis, and W. O. Johnson. 2000. Estimation of sensitivity and specificity of diagnostic tests and disease prevalence when the true disease state is unknown. Prev. Vet. Med. 45:61-81. http://dx.doi.org/10.1016/S0167-5877(00)00117-3.

Fosgate, G. T., I. M. Petzer, and J. Karzis. 2013. Sensitivity and specificity of a hand-held milk electrical conductivity meter compared to the California Mastitis Test for mastitis in dairy cattle. Vet. J. 196:98-102. http://dx.doi.org/10.1016/j.tvjl.2012.07.026.

Fox, L. 2013. Can somatic cells get too low? A question to be revisited. Pages 55-63 in Natl. Mastitis Counc. Ann. Mtg. Proc., San Diego, CA. Natl. Mastitis Counc., Inc., Madison, WI.

Georgiadis, M. P., W. O. Johnson, I. A. Gardner, and R. Singh. 2003. Correlation-adjusted estimation of sensitivity and specificity of two diagnostic tests. J. R. Stat. Soc. Ser. C. Appl. Stat. 52:63-76. http://dx.doi.org/10.1111/1467-9876.00389.

Gurjar, A., G. Gioia, Y. Schukken, F. Welcome, R. Zadoks, and P. Moroni. 2012. Molecular diagnostics applied to mastitis problems on dairy farms. Vet. Clin. North Am. Food Anim. Pract. 28:565-576. http://dx.doi.org/10.1016/j.cvfa.2012.07.011.

Hiss, S., M. Mielenz, R. M. Bruckmaier, and H. Sauerwein. 2004. Haptoglobin concentrations in blood and milk after endotoxin challenge and quantification of mammary $\mathrm{Hp}$ mRNA expression. J. Dairy Sci. 87:3778-3784. http://dx.doi.org/10.3168/jds.S00220302(04)73516-X.

Hiss, S., U. Mueller, A. Neu-Zahren, and H. Sauerwein. 2007. Haptoglobin and lactate dehydrogenase measurements in milk for the identification of subclinically diseased udder quarters. Vet. Med. (Praha) 52:245-252.

Holdaway, R. J., C. W. Holmes, and I. J. Steffert. 1996. A comparison of indirect methods for diagnosis of subclinical intramammary infection in lactating dairy cows. Part 2: The discriminative ability of eight parameters in foremilk from individual quarters and cows. Aust. J. Dairy Technol. 51:72-78.

Hui, S. L., and S. D. Walter. 1980. Estimating the error rates of diagnostic tests. Biometrics 36:167-171.

Koop, G., T. van Werven, N. Toft, and M. Nielen. 2011. Estimating test characteristics of somatic cell count to detect Staphylococcus aureus-infected dairy goats using latent class analysis. J. Dairy Sci. 94:2902-2911. http://dx.doi.org/10.3168/jds.2010-3929.
Le Roux, Y., F. Laurent, and F. Moussaoui. 2003. Polymorphonuclear proteolytic activity and milk composition change. Vet. Res. 34:629-645. http://dx.doi.org/10.1051/vetres:2003021.

Lippolis, J.D., T. A. Reinhardt, J. P. Goff, and R. L. Horst. 2006. Neutrophil extracellular trap formation by bovine neutrophils is not inhibited by milk. Vet. Immunol. Immunopathol. 113:248-255. http://dx.doi.org/10.1016/j.vetimm.2006.05.004.

Lippolis, J. D., and T. A. Reinhardt. 2005. Proteomic survey of bovine neutrophils. Vet. Immunol. Immunopathol. 103:53-65. http:// dx.doi.org/10.1016/j.vetimm.2004.08.019.

Lu, T. S. D. Kobayashi, M. T. Quinn, and F. R. Deleo. 2012. A NET outcome. Front. Immunol. 3:365 http://dx.doi.org/10.3389/ fimmu.2012.00365.

Maddau, L., A. Cabras, A. Franceschini, B. T. Linaldeddu, S. Crobu, T. Roggio, and D. Pagnozzi. 2009. Occurrence and characterization of peptaibols from Trichoderma citrinoviride, an endophytic fungus of cork oak, using electrospray ionization quadrupole timeof-flight mass spectrometry. Microbiology 155:3371-3381. http:// dx.doi.org/10.1099/mic.0.030916-0.

Mattila, T., S. Pyörälä, and M. Sandholm. 1986. Comparison of milk antitrypsin, albumin, N-acetyl- $\beta$-D-glucosaminidase, somatic cells and bacteriological analysis as indicators of bovine subclinical mastitis. Vet. Res. Commun. 10:113-124.

McDonald, T. L., M. A. Larson, D. R. Mack, and A. Weber. 2001. Elevated extrahepatic expression and secretion of mammary-associated serum amyloid A 3 (M-SAA3) into colostrum. Vet. Immunol. Immunopathol. 83:203-211.

Merrifield, R. B. 1963. Solid phase peptide synthesis. I. The synthesis of a tetrapeptide. J. Am. Chem. Soc. 85:2149-2154. http://dx.doi. org/10.1021/ja00897a025.

Miglio, A., L. Moscati, G. Fruganti, M. Pela, E. Scoccia, A. Valiani, and C. Maresca. 2013. Use of milk amyloid A in the diagnosis of subclinical mastitis in dairy ewes. J. Dairy Res. 80:496-502. http://dx.doi.org/10.1017/S0022029913000484.

Mura, S., G. Greppi, A. M. Roggio, L. Malfatti, and P. Innocenzi. 2011. Polypeptide binding to mesostructured titania films. Microporous Mesoporous Mater. 142:1-6. http://dx.doi.org/10.1016/j. micromeso.2010.10.047.

Murakami, M., R. A. Dorschner, L. J. Stern, K. H. Lin, and R. L. Gallo. 2005. Expression and secretion of cathelicidin antimicrobial peptides in murine mammary glands and human milk. Pediatr. Res. 57:10-15. http://dx.doi.org/10.1203/01. PDR.0000148068.32201.50.

National Mastitis Council. 1999. Laboratory Handbook on Bovine Mastitis. National Mastitis Council, Madison, WI.

Nielsen, N. I., T. Larsen, M. Bjerring, and K. L. Ingvartsen. 2005. Quarter health, milking interval, and sampling time during milking affect the concentration of milk constituents. J. Dairy Sci. 88:31863200. http://dx.doi.org/10.3168/jds.S0022-0302(05)73002-2.

Nyman, A. K., U. Emanuelson, and K. P. Waller. 2016. Diagnostic test performance of somatic cell count, lactate dehydrogenase, and $\mathrm{N}$-acetyl- $\beta$-D-glucosaminidase for detecting dairy cows with intramammary infection. J. Dairy Sci. 99:1440-1448. http://dx.doi. org/10.3168/jds.2015-9808.

O'Mahony, M. C., A. M. Healy, D. Harte, K. G. Walshe, P. R. Torgerson, and M. L. Doherty. 2006. Milk amyloid A: Correlation with cellular indices of mammary inflammation in cows with normal and raised serum amyloid A. Res. Vet. Sci. 80:155-161. http:// dx.doi.org/10.1016/j.rvsc.2005.05.005.

Piepers, S., Y. H. Schukken, P. Passchyn, and S. De Vliegher. 2013. The effect of intramammary infection with coagulase-negative staphylococci in early lactating heifers on milk yield throughout first lactation revisited. J. Dairy Sci. 96:5095-5105. http://dx.doi. org $/ 10.3168 /$ jds.2013-6644.

Pisanu, S., T. Cubeddu, D. Pagnozzi, S. Rocca, C. Cacciotto, A. Alberti, G. Marogna, S. Uzzau, and M. F. Addis. 2015. Neutrophil extracellular traps in sheep mastitis. Vet. Res. 46:59. http:// dx.doi.org/10.1186/s13567-015-0196-x.

Pyörälä, S. 2003. Indicators of inflammation in the diagnosis of mastitis. Vet. Res. 34:565-578. 
Reinhardt, T. A., R. E. Sacco, B. J. Nonnecke, and J. D. Lippolis. 2013. Bovine milk proteome: Quantitative changes in normal milk exosomes, milk fat globule membranes and whey proteomes resulting from Staphylococcus aureus mastitis. J. Proteomics 82:141-154. http://dx.doi.org/10.1016/j.jprot.2013.02.013.

Ruegg, P. L., and J. C. F. Pantoja. 2013. Understanding and using somatic cell counts to improve milk quality. Ir. J. Agric. Food Res. 52:101-117.

Saad, A. M., and K. Ostensson. 1990. Flow cytofluorometric studies on the alteration of leukocyte populations in blood and milk during endotoxin-induced mastitis in cows. Am. J. Vet. Res. 51:16031607.

Schepers, A. J., T. J. G. M. Lam, Y. H. Schukken, J. B. M. Wilmink, and W. J. A. Hanekamp. 1997. Estimation of variance components for somatic cell counts to determine thresholds for uninfected quarters. J. Dairy Sci. 80:1833-1840. http://dx.doi.org/10.3168/ jds.S0022-0302(97)76118-6.

Schukken, Y. H., R. N. González, L. L. Tikofsky, H. F. Schulte, C. G. Santisteban, F. L. Welcome, G. J. Bennett, M. J. Zurakowski, and R. N. Zadoks. 2009. CNS mastitis: Nothing to worry about? Vet. Microbiol. 134:9-14. http://dx.doi.org/10.1016/j. vetmic.2008.09.014

Schukken, Y. H., D. J. Wilson, F. Welcome, L. Garrison-Tikofsky, and R. N. Gonzalez. 2003. Monitoring udder health and milk quality using somatic cell counts. Vet. Res. 34:579-596. http://dx.doi. org/10.1051/vetres:2003028.

Sladek, Z., D. Rysanek, H. Ryznarova, and M. Faldyna. 2005. Neutrophil apoptosis during experimentally induced Staphylococcus aureus mastitis. Vet. Res. 36:629-643. http://dx.doi.org/10.1051/ vetres:2005023.

Smolenski, G., S. Haines, F. Y. S. Kwan, J. Bond, V. Farr, S. R. Davis, K. Stelwagen, and T. T. Wheeler. 2007. Characterisation of host defense proteins in milk using a proteomic approach. J. Proteome Res. 6:207-215.

Smolenski, G. A., R. J. Wieliczko, S. M. Pryor, M. K. Broadhurst, T. T. Wheeler, and B. J. Haigh. 2011. The abundance of milk cathelicidin proteins during bovine mastitis. Vet. Immunol. Immunopathol. 143:125-130. http://dx.doi.org/10.1016/j.vetimm.2011.06.034.

Trend, S., T. Strunk, J. Hibbert, C. H. Kok, G. Zhang, D. a. Doherty, P. Richmond, D. Burgner, K. Simmer, D. J. Davidson, and A. J. Currie. 2015. Antimicrobial protein and peptide concentrations and activity in human breast milk consumed by preterm infants at risk of late-onset neonatal sepsis. PLoS ONE 10:e0117038 http:// dx.doi.org/10.1371/journal.pone.0117038.

van Smeden, M., C. A. Naaktgeboren, J. B. Reitsma, K. G. M. Moons, and J. A. H. de Groot. 2014. Latent class models in diagnostic studies when there is no reference standard-A systematic review. Am. J. Epidemiol. 179:423-431. http://dx.doi.org/10.1093/aje/ kwt286.

Viguier, C., S. Arora, N. Gilmartin, K. Welbeck, and R. O'Kennedy. 2009. Mastitis detection: Current trends and future perspectives. Trends Biotechnol. 27:486-493. http://dx.doi.org/10.1016/j. tibtech.2009.05.004.

Vissio, C., S. A. Dieser, H. L. Agnelli, L. M. Odierno, and A. J. Larriestra. 2014. Accuracy of the composite somatic cell count to detect intramammary infection in dairy cows using latent class analysis. Prev. Vet. Med. 113:547-555. http://dx.doi. org/10.1016/j.prevetmed.2013.11.016.

Walker, J. B., P. J. Rajala-Schultz, W. L. Walker, J. L. Mathews, W. A. Gebreyes, and F. J. DeGraves. 2011. Variation in daily shedding patterns of Staphylococcus aureus in naturally occurring intramammary infections. J. Vet. Diagn. Invest. 23:1114-1122. http:// dx.doi.org/10.1177/1040638711425587.

Wheeler, T. T., G. A. Smolenski, D. P. Harris, S. K. Gupta, B. J. Haigh, M. K. Broadhurst, A. J. Molenaar, and K. Stelwagen. 2012 Host-defence-related proteins in cows' milk. Animal 6:415-422. http://dx.doi.org/10.1017/S1751731111002151.

Whelehan, C. J., A. Barry-Reidy, K. G. Meade, P. D. Eckersall, A. Chapwanya, F. Narciandi, A. T. Lloyd, and C. O'Farrelly. 2014. Characterisation and expression profile of the bovine cathelicidin gene repertoire in mammary tissue. BMC Genomics 15:128. http://dx.doi.org/10.1186/1471-2164-15-128.

Whyte, D., M. Walmsley, A. Liew, R. Claycomb, and G. Mein. 2005. Chemical and rheological aspects of gel formation in the California Mastitis Test. J. Dairy Res. 72:115-121.

Wiesner, J., and A. Vilcinskas. 2010. Antimicrobial peptides: The ancient arm of the human immune system. Virulence 1:440-464.

Zanetti, M. 2004. Cathelicidins, multifunctional peptides of the innate immunity. J. Leukoc. Biol. 75:39-48. http://dx.doi.org/10.1189/ jlb.0403147.

Zanetti, M. 2005. The role of cathelicidins in the innate host defenses of mammals. Curr. Issues Mol. Biol. 7:179-196.

Zanetti, M., L. Litteri, G. Griffiths, R. Gennaro, and D. Romeo. 1991. Stimulus-induced maturation of probactenecins, precursors of neutrophil antimicrobial polypeptides. J. Immunol. 146:4295-4300.

Zhang, L., S. Boeren, C. M. van Hooijdonk, J. M. Vervoort, and K. a. Hettinga. 2015. A proteomic perspective on the changes in milk proteins due to high somatic cell count. J. Dairy Sci. 98:5339-5351. http://dx.doi.org/10.3168/jds.2014-9279. 